\title{
Langerhans cell histiocytosis in children - a disease with many faces. Recent advances in pathogenesis, diagnostic examinations and treatment
}

\author{
Michalina Jezierska ${ }^{1}$, Joanna Stefanowicz ${ }^{1}$, Grzegorz Romanowicz ${ }^{2}$, Wojciech Kosiak ${ }^{1}$, Magdalena Lange ${ }^{3}$ \\ ${ }^{1}$ Department of Pediatrics, Hematology and Oncology, Medical University of Gdansk, Gdansk, Poland \\ ${ }^{2}$ Department of Nuclear Medicine, Medical University of Gdansk, Gdansk, Poland \\ ${ }^{3}$ Department of Dermatology, Venereology, and Allergology, Medical University of Gdansk, Gdansk, Poland
}

Adv Dermatol Allergol 2018; XXXV (1): 6-17

DOI: https://doi.org/10.5114/pdia.2017.67095

\begin{abstract}
Langerhans cell histiocytosis is a rare clonal disease characterized by the proliferation of CD1a-positive immature dendritic cells. The purpose of this article was to present an updated review of recent advances in the pathogenesis, clinical features, imaging and treatment of this disease. The discovery of oncogenic BRAF mutations and the presence of proinflammatory cytokines and chemokines confirmed the unusual characteristics of this disease. Currently, children with organ involvement who do not have a good response to chemotherapy and have neurodegeneration or diabetes insipidus are the most problematic patients. Further research is needed to improve the results of treatment.
\end{abstract}

Key words: Langerhans cell histiocytosis, children, pathogenesis, symptoms, treatment.

\section{Introduction}

Langerhans cell histiocytosis (LCH) is a rare clonal disease of the monocyte-macrophage system characterized by uncontrolled proliferation and accumulation of $\mathrm{CD}^{2} \mathrm{a}^{+} /$ CD207+ dendritic cells (DCs) as a result of continuous immune stimulation [1].

Its clinical presentation is highly variable and may range from isolated, self-healing skin and bone lesions to life-threatening multi-system disease. Reaching an appropriate diagnosis in a short time is a significant challenge. Extremely wide symptomatology is associated with formations in various tissues and organ infiltrations that consist of pathological DCs that are morphologically similar to epidermal Langerhans cells.

The histiocytic disorders are generally defined by their constitutive cell type, on the basis of widely recognized pathologic and histological criteria. In light of recent insights Emile et al. proposed to parsimoniously gather the large number of categories of histiocytic disorders into 5 groups (Table 1) [1]. The nomenclature of histiocytic disorders has changed in the last 50 years. Historically LCH was called "histiocytosis X", which is a term that includes three entities: eosinophilic granu- loma, Hand-Schüller-Christian disease and Letterer-Siwe disease [2-6].

At present, $\mathrm{LCH}$ is classified into three distinct forms: single-system single site (SS-S), single-system multi-site (SS-m), and a multisystem type (MS) [7-10]. Approximately $65 \%$ of patients have SS disease [11-13]. An epidemiological Japanese study reported that the SS-S, SS-m, and MS forms of $\mathrm{LCH}$ are diagnosed at a ratio of almost $1: 1: 1$ [12]. In SS-S LCH, 70-82\% of patients have bone lesions, and only $12 \%$ have skin lesions $[12,14]$. Multisystem LCH may have two forms, either with or without organ involvement. Low-risk organs include the skin, bones, lymph nodes, and the pituitary gland, whereas high-risk organs include bone marrow, liver, spleen and the lungs $[2,3,7,9]$. The latest studies have not confirmed that the lungs are risk organs $[15,16]$.

The involvement of specific organs affects the course, treatment and prognosis of $\mathrm{LCH}[2,3,7,17]$.

\section{Epidemiology}

Langerhans cell histiocytosis can occur at any age. However, peak occurrence occurs between 1 and 4 years 
of age. The incidence of LCH in children is determined as 2-9/1000 000/year and is slightly predominant in males $(\mathrm{M} / \mathrm{F}=1.2-1.4)[6,8,13,14,18]$.

\section{Aetiology and pathogenesis}

The nature of the disease still raises doubts. For many years, debates over models of LCH pathogenesis focused on functional dysregulations versus malignant transformation of epidermal DCs. The detection of some virus DNA sequences in peripheral blood and tissues and the associated Epstein-Barr virus infection with LCH suggested that LCH is reactive $[19,20]$. Langerhans cell histiocytosis lesions include infiltrating pathological DCs (8\%), macrophages, eosinophils and lymphocytes enriched for regulatory $T$ cells. Dendritic cells express high levels of T-cell costimulatory molecules and proinflammatory cytokines. Cytokines, chemokines, and cytokine/chemokine receptors constitute the "cytokine storm" [5, 21-23]. Recently, it was reported that DCs abundantly express the pleiotropic cytokine osteopontin, which promoted the generation of T helper cells, recruited histiocytes/monocytes and activated osteoclasts, which in turn produced large amounts of tissue-destructive enzymes [17, 22]. Murakami et al. found that LCH patients had high serum levels of IL-17A and that IL-17A receptor expression levels helped to distinguish between LCH forms [24]. Biopsies of lesions from both SS and MS disease were found to have proliferation of DCs from a single clone [25, 26]. Despite clonality, pathological DCs do not appear dysplastic, mitoses are rarely observed, and chromosomes are typically intact $[23,27]$. Clonal proliferation leading to the formation of the infiltrates and the discovery of the mutually exclusive activating somatic BRAF V600E (57\%) and MAP2K1 gene mutations that occur in approximately $75 \%$ of patients suggest there is a neoplastic process $[5,28,29]$. The BRAF V600E mutations lead to constitutive activation of the downstream kinases MEK and $\operatorname{ERK}[27,30]$. The presence of circulating cells carrying BRAF V600E mutations is associated with high-risk clinical status (multisystem disease and liver, bone marrow, spleen involvement) and with a two-fold increase in the risk of recurrence [31]. Haematopoietic cell progenitors with the BRAF V600E mutation were also identified in patients with high-risk LCH. The new evidence supported a model in which LCH occurs as a consequence of a misguided differentiation programme of myeloid DC precursors. Genetic, molecular and functional data implicate activation of the ERK signalling pathway at critical stages in myeloid differentiation as an essential and universal driver of LCH pathology. The low-risk disease arises from ERK activation in tissue-restricted precursors [27, 31]. The frequency of BRAF V6O0E mutations in LCH depends on ethnicity [29].
Table 1. The revised classification system of histiocytoses and neoplasms of macrophage-dendritic cell lineages [1]

\begin{tabular}{|c|c|c|}
\hline No. & $\begin{array}{l}\text { Group of } \\
\text { histiocytic } \\
\text { disorders }\end{array}$ & Histiocytosis \\
\hline 1 & L group & $\begin{array}{l}\mathrm{LCH} \\
\mathrm{ICH}: \\
-\mathrm{ECD} \\
\text { Mixed LCH/ECD }\end{array}$ \\
\hline 2 & C group & $\begin{array}{l}\text { Cutaneous non-LCH: } \\
\text { - XG family: JXG, AXG, SRH, BCH, GEH, PNH } \\
\text { - Non-XG family: cutaneous RDD, NXG, } \\
\text { other not otherwise specified } \\
\text { Cutaneous non-LCH with a major systemic } \\
\text { component: } \\
\text { - XG family - XD } \\
\text { - Non-XG family - MRH }\end{array}$ \\
\hline 3 & M group & $\begin{array}{l}\text { Primary } \mathrm{MH} \\
\text { Secondary } \mathrm{MH} \text { (following or associated with } \\
\text { another hematologic neoplasia) }\end{array}$ \\
\hline 4 & R group & $\begin{array}{l}\text { Familial RDD } \\
\text { Sporadic RDD: } \\
\text { - Classical (nodal) } \\
\text { - Extra-nodal } \\
\text { - RDD with neoplasia or immune disease } \\
\text { - Other, non-C, non-L, non-M, non-H } \\
\quad \text { histiocytoses }\end{array}$ \\
\hline 5 & H group & $\begin{array}{l}\text { Primary HLH: Mendellan inherited } \\
\text { conditions leading to HLH } \\
\text { Secondary HLH (non-Mendelian HLH) } \\
\text { HLH of unknown/uncertain origin }\end{array}$ \\
\hline
\end{tabular}

$A X G$ - adult xanthogranuloma, $B C H$ - benign cephalic histiocytosis, ECD Erdheim-Chester disease, GEH - generalized eruptive histiocytosis, HLH - haemophagocytic lymphohistiocytosis, ICH - indeterminate cell histiocytosis, JXG - juvenile xanthogranuloma, LCH - Langerhans cell histiocytosis, $\mathrm{MH}$ - malignant histiocytoses, MRH - multicentric reticulohistiocytosis, $N X G$ - necrobiotic xanthogranuloma, $P N H$ - progressive nodular histiocytosis, $R D D$ - Rosai-Dorfman disease, $S R H$ - solitary reticulohistiocytoma, XD - xanthoma disseminatum, $X G$-xanthogranuloma.

\section{Diagnosis}

The diagnosis of LCH is based on histological criteria established by the Histiocyte Society in 1987 [7, 21]. To make a diagnosis, it is necessary to perform a histological examination with immunophenotyping. The identification of characteristic cells and the presence of markers, such as CD1a and/or CD207 (Langerin), allows for a definitive diagnosis of LCH. The Birbeck granule is a LCH-specific tennis racquet-shaped organelle detected by electron microscopy. The presence of Birbeck granules, once considered the "gold standard" in the diagnostics, currently does not have to be assessed. They have been replaced by langerin, which is a cell-surface receptor that induces formation of Birbeck granules [17, 32].

\section{Clinical presentation of $\mathrm{LCH}$}

The disease has different clinical courses from a mild form, which is limited to one organ, to a severe form with 
the involvement of many organs and systems that progresses very quickly $[2,8,17]$. The clinical presentation of $\mathrm{LCH}$ includes a wide range of symptoms, from symptoms of severe life-threatening systemic diseases, such as septic fever with accompanying haemorrhagic rash and hepatosplenomegaly, to the presence of lumps under the skin with little specificity or a single asymptomatic bone focus $[2,6,10,17,33]$.

For this reason, LCH presents many diagnostic and therapeutic difficulties. Langerhans cell histiocytosis lesions may spontaneously regress or repeatedly reactivate, which contributes to long-term disabilities, such as diabetes insipidus (DI) and neurodegenerative disease $[10,17,18,33,34]$. Approximately $30-40 \%$ of patients develop lasting negative consequences [35-38].

Langerhans cell histiocytosis can be completely asymptomatic. The most frequent presenting signs and symptoms of LCH include painful bone lesions and rash. Often non-specific symptoms become prominent, such as fever, poor appetite, weight loss, fatigue, irritability and changes in behaviour $[17,18]$. Finally, more characteristic symptoms associated with the involvement of bones, skin, the pituitary gland, liver, spleen, the haematopoietic system, lungs, lymph nodes, the central nervous system (CNS), thymus, and the gastrointestinal tract, may appear (Table 2) [2, 4, 5, 9].

In the youngest children, the disease is often an MS disease with fever and symptoms of failure in various organs $[2,10,14]$. In a Japanese study, the patients with skin lesions were younger than those with bone lesions [12]. In a previous French study, $77 \%$ of the patients with the skin lesion were less than 1 year old [14].
The prognosis of LCH varies depending on its form. The prognosis of patients with SS-S LCH is generally good [12]. However, the patients with the involvement of the craniofacial bone(s) (orbital, temporal, mastoid, sphenoidal, zygomatic, ethmoidal bones, the maxilla, paranasal sinuses, or anterior or middle cranial fossa) with intracranial soft tissue extension (the so-called CNS-risk lesion(s)) had a higher risk for developing DI [39]. The LCH-III protocol study conducted by the Histiocyte Society suggested that chemotherapy should be offered to these patients, even if there was only a single lesion [40]. At present, the factors for poor prognosis are age under 2 years old, MS disease, high-risk organ involvement and dysfunction or a poor response to initial therapy $[2,3,7$, 41, 42]. It is believed that hepatic involvement at the time of the diagnosis is particularly associated with a poor prognosis [6].

\section{Bones}

Bones are involved in approximately $80 \%$ of $\mathrm{LCH}$ patients $[2,14,33,43]$. Unifocal involvement is more common than multifocal involvement [43]. Langerhans cell histiocytosis can involve any bone, but there is a predilection for the axial skeleton, with more than $50 \%$ of bone lesions occurring in the flat bones (skull, ribs, pelvis). In the long bones, the femur is the most commonly affected, followed by the humerus, tibia and vertebrae ("vertebra plana") [17, 44]. The symptoms include pain, swelling of the affected area and pathological fractures. The location of lesions in the vertebral column may cause compression fractures and scoliosis [10, 17, 43]. There may be visual loss or exophthalmos due to orbital involve-

Table 2. Incidence and symptomatology of systems and organs involvement in Langerhans cell histiocytosis in children $[1,2,4,5,9]$

\begin{tabular}{|c|c|c|c|c|}
\hline No. & System involved & Organ involved & Symptomatology & Incidence \\
\hline \multirow[t]{3}{*}{1} & \multirow[t]{3}{*}{ Skeletal } & $\begin{array}{l}\text { Flat and long bones, spine/skullcap } \\
\text { bones, femurs, humeri, spine }\end{array}$ & Bone pains, lumps & \multirow[t]{3}{*}{$80 \%$} \\
\hline & & Orbital cavity & Exophthalmos & \\
\hline & & Temporal bone & Discharge from the middle ear, hearing loss & \\
\hline 2 & Integumentary & Skin & Seborrhoeic erythematous rash, haemorrhagic rash & $60 \%$ \\
\hline \multirow[t]{3}{*}{3} & \multirow[t]{3}{*}{ Lymphatic } & Lymph nodes & Swollen lymph nodes & $33 \%$ \\
\hline & & Thymus & Widened opacity of the mediastinum & $2.6 \%$ \\
\hline & & Spleen & Splenomegaly, cytopenias & $15 \%$ \\
\hline 4 & Liver & Liver & Hepatomegaly, liver dysfunction & $15 \%$ \\
\hline 5 & Respiratory & Lungs & Respiratory failure & $1-15 \%$ \\
\hline 6 & Bone marrow cavity & Bone marrow & Neutropenia, anaemia, thrombocytopenia & $15-30 \%$ \\
\hline \multirow[t]{2}{*}{7} & \multirow[t]{2}{*}{ CNS } & Hypothalamic-pituitary disease & $\begin{array}{l}\text { Diabetes insipidus, short stature, secondary } \\
\text { hydrocephalus, cranial nerve palsies }\end{array}$ & \multirow[t]{2}{*}{$25 \%$} \\
\hline & & CNS & Neurodegenerative disease of the CNS & \\
\hline 8 & Digestive & Gastrointestinal tract & Haemorrhagic diarrhoea, anaemia & $<5 \%$ \\
\hline
\end{tabular}


ment $[4,43]$. The involvement of the temporal bone is manifested by symptoms imitating the inflammation of its structures - the middle ear and the mastoid process with the typical recurrent ear discharge, secondary hearing deterioration and even deafness [17, 43]. Histiocytic infiltrates in the upper and lower jaws cause swelling and looseness of gums and teeth ("loose teeth syndrome") $[43,44]$. The typical radiographic findings are a solitary lytic lesion of the skull and a "vertebra plana" [17, 43, 44].

\section{Skin}

Skin lesions are the second most-common clinical manifestation of LCH (30-60\%) [17, 33], which is particularly frequent in infants [17] and the most common presentation of "non-self-regressive" cutaneous LCH in neonates and young infants [45]. However, an isolated cutaneous form of the disease is rare (the number of described cases does not exceed $12 \%$ of all patients with $\mathrm{LCH}$ ), typically concerns only male infants and has a good prognosis $[12,46]$. However, both patients born with skinonly LCH and patients who develop skin-only LCH during infancy can have a "self-healing" disease with spontaneous regression or may progress to MS-LCH with a worse prognosis [47]. The special form of congenital cutaneous LCH in neonates is uncommon Hashimoto-Pritzker disease characterized by self-regressive red-brown cutaneous nodules $[45,47]$. The skin disease in patients older than 18 months of age at diagnosis is associated with the presence of MS-LCH [48]. The incidence of cutaneous involvement is significantly higher in children with MS disease (53\%) [48]. Skin lesions may take different forms and different degrees of severity. The eruption may be extensive and involve the scalp, face, trunk, buttocks and intertriginous area. The trunk is the most affected site [48]. A wide spectrum of cutaneous presentations varying from crusted or scaly nodules and papules, blisters, vascular tumour-like lesions, and scaling orange to red or purpuric macules (frequently in seborrhoeic region) was documented by Morren et al. [11]. Crusted or scaly papules and papulovesicles are the most common presentation of skin LCH [11]. In early childhood, they often take the form of bumps and blisters. On the other hand, a maculopapular desquamative rash, which is located mainly within the scalp, retroauricular, inguinal or axillary area, can also appear in older children. Among other lesions occurring in the course of the disease, nodules and petechiae should be listed [46]. Sometimes there are superficial ulcerations of the lesions accompanied by oozing as the result of secondary processes leading to a bacterial superinfection. Ulcerative lesions behind the ears or involving the scalp, axillae, genitalia, or perianal region are often misdiagnosed as bacterial or fungal infections. Rare lesions include a haemangioma-like lesion, a varicella-like eruption, or purpura. "Blueberry muffin baby syndrome" has also been described as a presentation of $\mathrm{LCH}$ in neonates [49]. A seborrhoea-like eruption on the scalp and lesions in the large body folds were also more frequent in the group with MS-LCH, with these lesions being more erosive and ulcerative compared to the skinonly group [11]. Late onset and a protracted course of skin lesions were associated with MS LCH, whereas wild-type and mutated BRAF were found in rapidly resolving skin lesions. The involvement of the hands and feet suggests there is a self-regressive form, and necrosis might also be associated with a good prognosis [45]. Moreover, there are reports of changes in nails in $\mathrm{LCH}$, but it is unclear whether the change predicts a poor prognosis, although lung involvement has been described in approximately $50 \%$ of such patients [50]. Nail involvement can occur in the form of longitudinal grooving, onycholysis, subungual hyperkeratosis, subungual pustules, purpuric striae of the nail bed, V-shaped notches, pterygium formation, and end elkonyxis (oval depression in the nail plate). Paronychial erythema and swelling as well as nail-fold destruction have also been reported. The histology of nail lesions is similar to cutaneous forms (infiltrations of typical Langerhans cells) [50].

\section{Lymph nodes}

The cervical nodes are most frequently involved and may be soft or hard-matted groups with accompanying lymphoedema [10, 51].

\section{Oral mucosa}

The symptoms of oral LCH include gingival hypertrophy and ulcers of the soft and hard palate, buccal mucosa, or on the tongue and lips. Early eruption of teeth occurs with LCH infiltration of the mandible or maxilla $[52,53]$.

\section{Central nervous system}

The involvement of the CNS is one of the rarer forms of LCH (24\% of all LCH children) [54]. Central nervous system lesions based on MRI include active lesions involving hypothalamic-pituitary disease, space-occupying lesions at other sites (the meninges, the choroid plexus, the pineal gland, the cerebellar parenchyma), and neurodegenerative lesions of the cerebellum, pons, brainstem, basal ganglia, grey or white matter of the brain [55-57]. The most common MRI changes include solid enlargement of the pineal gland, a thickened enhancing stalk and signal changes of the dentate nuclei [58]. The involvement of the hypothalamus and the pituitary gland, which are manifested by DI, is the most common known form of CNS LCH (15-30\% of LCH patients) [37, 39, 59]. Fifty-six percent of LCH patients with DI will develop anterior pituitary hormone deficiencies within 10 years of DI onset [60]. These patients may present growth deficiency (which may affect up to $10 \%$ of LCH patients), precocious or delayed puberty, galactorrhoea and symptoms of hypothyroidism, and in the case of hypothalamus infiltra- 
tions (rare), there are typically changes in behaviour, eating, sleep, or thermoregulation disorders. Lesions in the pituitary and hypothalamus may be accompanied by foci of histiocytic infiltrates associated with the meninges and choroid plexuses. The patient may then complain of headaches, vomiting, or blurred vision, or display convulsions and other focal symptoms. DI occurs more often in patients with craniofacial bone, ear, eye and/or oral lesions, known CNS-risk lesions [39, 59, 61].

The syndrome of neurodegenerative central nervous system Langerhans cell histiocytosis (ND-CNS-LCH) is less known, develops in approximately $1-3 \%$ of LCH patients and remains a progressive and devastating complication. It is initially manifested by subtle neurological deficits that can enhance and develop years after the first LCH symptoms. The deficits include ataxia, dysarthria, tremor, vertigo, nystagmus, psychomotor development delay, behavioural disorders, and neuropsychological deficits. Patients at high risk for developing ND-CNS-LCH are usually children with MS-LCH, or DI, or have involvement of the temporal, petrous, orbital, and zygomatic bones $[57,59,62]$. The studies by Grois et al. showed that $75 \%$ of patients with DI had changes that were visible in the MRI in the bones of the facial skeleton, and as many as $76 \%$ of these patients in their check-up MRI examination conducted 5 or more years after a diagnosis of diabetes insipidus showed parenchymal, neurodegenerative changes in their encephalon [61]. The risk of LCH within the CNS in these cases is 10 times higher than in patients with SS-LCH. ND-CNS-LCH occurs more frequently in young patients who present with skull/facial lesions at LCH onset $[63,64]$.

The pathogenesis of these disorders is not fully explained and probably involves intracranial immune interactions and inflammatory mechanisms between LCH cells/T cells and glial cells around microvessels in the CNS. Microglia activation, gliosis, and neuronal and axonal destruction with secondary demyelination are typical [57, 63]. ND-CNS-LCH may be a consequence of undetectable active disease or paraneoplastic syndrome with DC activation of the immune system to recognize CNS antigens [62]. In recent years, MRI tests revealed the presence of pathological changes in the structures of the cerebellum - focal lesions, which are mostly periventricular in location, and hypodense foci consisting of demyelination changes and gliosis of the white matter [61]. The cerebellum is the most frequent and earliest site of involvement, and it is sometimes associated with the brainstem, basal ganglia and hemispheric white matter. MR spectroscopy showed a reduced cerebellar NAA/Cr ratio and may complement structural MRI $[58,65,66]$. Histopathology from cerebellar biopsies and autopsies revealed neuronal loss, axonal degeneration and profound T-cell inflammation without the infiltrates of cells characteristic for $\operatorname{LCH}[59,63]$. There is no correlation between the degree of neurological impairment and the topography, extent and grading of neurodegenerative lesions in most patients [65].

Both Imashuku and Krenova and Sterba underscore the necessity of cerebrospinal fluid examinations and neurocognitive/neurological/psychological assessments at the time of diagnosis in ND-CNS-LCH risk patients $[67,68]$.

\section{Liver}

The involvement of the liver in the course of LCH may be a primary or secondary process to, for example, the involvement of hepatic hilar lymph nodes. A typical symptom is hepatomegaly (in the diagnostic criteria liver $>3 \mathrm{~cm}$ below the costal margin in the midclavicular line in the USG). It may be accompanied by organ dysfunction, an increase of transaminases, hypoalbuminemia $(<30 \mathrm{~g} / \mathrm{dl})$ and secondary oedema or ascites, jaundice (bilirubin $>3 \times \mathrm{N}$ ) or clotting factor deficiencies [7, 9]. Ultrasonography (USG), computed tomography (CT) and magnetic resonance (MR) images of the liver typically show hypoechoic or low signal intensity along the portal veins or biliary tracts [69]. Langerhans cell histiocytosis may also be located within the bile duct, which may cause cholestasis, sclerosing cholangitis (15-25\% of LCH children), biliary cirrhosis and organ damage that require transplantation [70, 71]. Biopsies typically do not include histiocytes but demonstrate periportal lymphocytic infiltrates, bile duct inflammation, and loss of bile ducts. Seventy-five percent of children with sclerosing cholangitis will not respond to chemotherapy, and all of these patients require liver transplantation. The coexistence of liver involvement and sclerosing cholangitis or liver cirrhosis may hinder the diagnosis on account of the regression of Langerhans cells [71]. Liver involvement drastically changes a patient's prognosis and treatment [70]. In this group of patients, the 5 -year overall survival rate is only $25 \%$ [13].

\section{Spleen}

Spleen involvement may be the consequence of the primary or secondary process (portal hypertension as a result of periportal fibrosis). The diagnostic criterion for splenomegaly is the spleen image in the ultrasound ( $>2 \mathrm{~cm}$ below the costal margin in the midclavicular line). Splenomegaly may be accompanied by hypersplenism $[5,7,9]$.

\section{Mediastinum}

Mediastinal involvement is very rare in LCH $(2.6 \%$ of patients). Dendritic cells infiltrate mainly the thymus and lymph nodes [72]. This location concerns primarily younger children ( $<1$ year old). With age, its incidence decreases, although there are reports of diagnoses made in people $>18$ years old. This location predisposes to the occurrence of life-threatening conditions for the patient. The symptoms of mediastinal involvement include cough, tachypnoea, respiratory failure or superior vena 
cava syndrome. An enlarged thymus or involvement of the mediastinal lymph nodes can mimic lymphoma or an infection. Patients with LCH in the thymus and mediastinal lymph nodes usually already display MS-LCH at the time of diagnosis, and nearly half of them have one of the so-called 'risk organs' affected. More frequently, they have skin lesions, and the foci are rarely in the bones.

The group of patients with thymus involvement and mediastinal lymph nodes is considered to be particularly vulnerable to developing serious infections during treatment of the underlying disease, which is explained by the involvement of the thymus itself as well as a younger age at the time of diagnosis $[72,73]$.

\section{Bone marrow}

The occurrence of histiocytic infiltrates within the bone marrow causes haematopoietic failure that clinically manifests as anaemia, leukopenia, or thrombocytopenia. Bone marrow involvement occurs most frequently in young children who have diffuse disease involving the liver, spleen, lymph nodes, and skin, and it may be associated with marked thrombocytopenia or neutropenia. Other occurrences have only mild cytopenias and were found to have marrow involvement with LCH through sensitive immunohistochemical or flow cytometric analysis of the bone marrow [74]. Haematopoietic system involvement is a well-known prognostic factor in LCH. The study by Raney et al. revealed that among haematological dysfunction parameters, thrombocytopenia had the most significant effect on survival [75]. Langerhans cell histiocytosis patients with very high-risk disease may present haemophagocytosis that mimics haemophagocytic lymphohistiocytosis [76].

\section{Lungs}

Involvement of the lungs is the most characteristic for adults, in whom smoking is a key aetiological factor $[77,78]$. In the paediatric population, the isolated form of the disease affects less than $1 \%$ of $\mathrm{LCH}$ children $[15,16$, 79]. More often, the histiocytic lesions observed in the lungs are in the form of MS-LCH (up to 25\%) [16, 80]. The most common symptoms include non-productive cough and shortness of breath. Less frequent symptoms include pain in the chest, general malaise and fatigue, weight loss, fever, and cyanosis. Extremely rare haemoptysis can be observed in children [15]. In 10\% of children over the course of lung LCH, a pneumothorax typically develops, which is most frequently a unilateral one (although cases of bilateral lesions are also possible) and is often recurrent (on the same side or the opposite). Chest X-rays may show non-specific interstitial infiltrates with peribronchial thickening (100\%), cystic changes (39\%), and pneumothorax (11\%) [16]. A high-resolution CT of the chest is needed to visualize the cystic/nodular pattern of LCH that leads to the destruction of lung tissue. Declining diffusion capacity may also herald the onset of pulmonary hypertension. In adults, as a result of a long-term disease process, pulmonary fibrosis or pulmonary hypertension is observed, and in extreme cases it requires transplantation of the lungs or both the lungs and heart [15].

Howarth et al. reported $85 \%$ disease free-survival in children and adults with isolated lung involvement [78]. Currently, isolated pulmonary involvement is not considered to be an independent prognostic factor $[15,16]$.

\section{Gastrointestinal tract}

Gastrointestinal (GI) involvement in children with $\mathrm{LCH}$ is rare and has been associated with systemic illness and poor prognosis [81]. The peak incidence occurs in children $<2$ years old with a 2-fold male predominance [82]. The reported symptoms include vomiting, abdominal pain, intractable diarrhoea, a child's failure to gain weight, malabsorption, bloody stool, protein-losing enteropathy, and even intestinal perforation $[83,84]$. Through endoscopy, superficial erosions and haemorrhagic ulcerations are typically found throughout the GI tract [82]. A long-term disease process can lead to the development of fully symptomatic malabsorption or protein-losing enteropathy and complications such as intestinal perforation in extreme cases [81].

\section{Other lesions}

In addition to these locations of the disease, there have been unusual reports in the literature of thyroid, pancreas, kidney and salivary gland involvement [85-87].

\section{Recent advances in imaging evaluation}

Bone foci in LCH are lytic. X-rays typically demonstrate osteolytic "punched out" lesions with sharp margins. Radiography, which remains the gold standard for diagnostic and staging procedures, may be complemented by CT and/or MRI to delineate the extent of osseous destruction or the extent of bone marrow and soft tissue involvement [43]. Magnetic resonance imaging is necessary for the assessment of CNS-risk lesions and ND-CNSLCH $[54,58,61,88]$.

Recently, new imaging techniques, such as positron emission tomography-computed tomography (PET-CT) and whole body MRI, have been developed, allowing improved assessment of the extent and severity of the disease $[89,90]$. Positrone emission ET-CT is useful for detecting and assessing LCH lesion activity and for evaluating the response to treatment [91]. There are relatively few papers regarding FDG-PET in LCH compared to other malignancies. There are mostly case and multi-case reports or reviews but not prospective, systematic evaluations. This lack of research is due to the low incidence of the disease as well as a wide range of involvement and prognosis. However, FDG-PET has been studied for usefulness in staging, therapy response assessment and diagnosis of disease recurrence. Apart from a few reports 
on non-avid active LCH, the vast majority of lesions were found to have a significant increase in radiolabelled glucose uptake. The advantage of FDG-PET is that it is performed as a whole body scan with high sensitivity for lesion detection, which allows for more precise staging regardless of the location of disease active foci. With similar high diagnostic confidence, FDG-PET allows for evaluation of therapy responses. The ability to detect metabolically active LCH is crucial, especially for evaluating disease in bones where both bone scanning and conventional CT may show abnormalities due to bone remodelling in the lack of active disease. This approach helps to make management decisions in patients with LCH. Moreover, the level of glycolytic activity reflected in the tracer concentration (SUV measurement) may be considered an important factor in prognosis estimation. However, for sensitivity, it must be noted that the method is not specific and that there is no pathognomonic pattern of tracer uptake to indicate $\mathrm{LCH}$, so a differential diagnosis must be considered when reading scans. Nevertheless, there is a large amount of evidence of the superiority of FDG-PET compared to conventional imaging in the LCH evaluation. With the increased availability of the method as well as the decreasing cost of an examination, the cost-benefit ratio and cost effectiveness of FDG-PET are rising. The recent introduction of PET-MR systems also resulted in reduced radiation exposure, which is especially important for paediatric patients and patients requiring multiple scans, which can be common in cases of LCH [92].

The most important imaging for LCH patient assessment is ultrasonography. The use of a new imaging technique called static elastography for assessment of changes in the skull and other bones allows for more complete differential diagnoses because the typical images reveal hyperplastic (hard changes) and fluid changes (rainbow artefact or the artefact buffalo eye) in unicameral bone cysts (Figures 1, 2) [93].

\section{Treatment}

Treatment depends on the form of LCH. Systemic therapy is indicated for all patients with SS-m and MSLCH as well as for special localizations. A standard twodrug regimen with vinblastine and prednisone consisting of an initial intensive phase for 6-12 weeks, followed by maintenance therapy for a total treatment duration of at least 12 months, is recommended [7]. Non-responders, particularly those with progressive disease in a high-risk organ, are eligible for salvage therapy with cladribine, cytarabine, clofarabine or combinations of those medications as well as bone marrow and/or solid organ transplantation [3, 17, 48, 94].

Patients with SS-LCH limited to the skin may be observed. If the skin lesions do not spontaneously resolve, a variety of methods may be used, including topical ste- roids, oral methotrexate or thalidomide, topical nitrogen mustard, or psoralens with UV light [40]. A single bone lesion involving the frontal, parietal, occipital bones and any other bones may be treated by curettage only or curettage with a local injection of methylprednisolone [95]. Other skull lesions (mastoid, temporal or orbital) should be treated with chemotherapy to reduce the risk of DI and ND-CNS-LCH. Vertebral or femoral bone lesions at risk for collapse require isolated radiotherapy. Treatment of CNS lesions (enlargement of the hypothalamus and the pituitary gland or grey and white matter, the choroid plexus, and leptomeningeal lesions) includes systemic chemotherapy $[2,40]$.

There is no established optimal therapy for patients who develop ND-CNS-LCH. The ND-CNS-LCH is commonly treated with intravenous immunoglobulin alone or in combination with chemotherapy regimens [40, 62, 64, 96]. Moreover, retinoic acid [97], thalidomide and its analogues [98-100], as well as high doses of steroids [55, 100], have been proposed for the treatment of ND-CNSLCH. Cytotoxic-immunosuppressive approaches have included cladribine $[101,102]$ and cytarabine because of good CNS penetration $[9,17,56]$.

The possible therapeutic use of target therapy, at least in the subset of patients with BRAF V600E mutation (e.g., vemurafenib), should be confirmed in the near future $[103,104]$. In addition, recent prophylactic measures for preventing the development of ND-CNS-LCH were discussed by Krenova and Sterba and Imashuku et al. $[67,68]$. The remaining questions include which LCH patients and what drugs and methods (immunoglobulin or leukapheresis or appropriate intrathecal/ systemic chemotherapy or a molecular targeting agent) should be used.

The prognosis for LCH varies. It depends on the form of the disease (SS-LCH vs. MS-LCH) as well as its location and response to chemotherapy. In unifocal LCH involving a bone or an isolated skin lesion, the prognosis is good. There have been cases of spontaneous remission or symptoms subsiding after local treatment. In forms with multifocal bone involvement, relapses of the disease occur more often. In cases of extensive skin lesions, the likelihood of internal organ involvement increases even several years after the completion of the first-line treatment of the disease. The prognosis worsens significantly with the involvement of "risk organs" and the Gl tract. Spontaneous regression of the disease located in those areas is rare. Recurrence is one of the most important problems in the management of $\mathrm{LCH}$. Yagci et al. observed recurrence in nearly one-third of patients. New bone lesions were the most frequent finding at the time of recurrence [105]. Jubran et al. reported a seven-times higher risk of reactivation for patients with multiple bone lesions compared to patients who have single bone involvement [106]. 

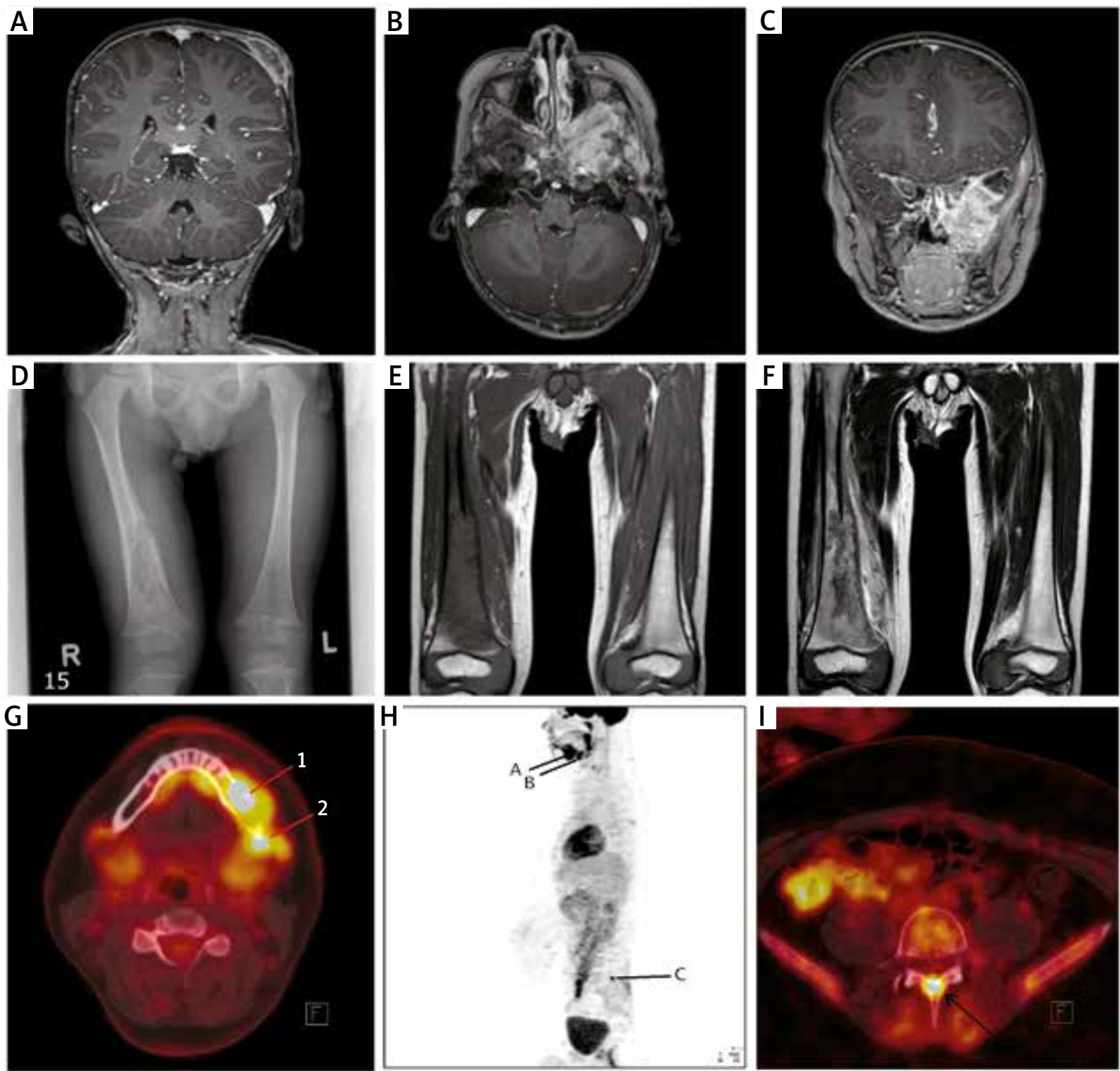

Figure 1. A - Magnetic resonance imaging (T1-weighted image) after contrast administration - osteolytic lesion of the parietal bone with soft tissue involvement. B - Magnetic resonance imaging (T1-weighted image) after contrast administration - extensive infiltration of the skull base (left side), horizontal projection. C - Magnetic resonance imaging (T1-weighted image) after contrast administration - extensive infiltration of the skull base (left side), vertical projection. D - X-ray, PA - osteolytic focus of the right femur with interruption of cortical layer and periosteal reaction. $\mathrm{E}$ - Magnetic resonance imaging (T1-weighted image) in the frontal plane - destruction of the distal shaft of the right femur. F-Magnetic resonance imaging (T2-weighted image) in the frontal plane - destruction of the distal shaft of the right femur. G - PET-CT FDG and CT fusion image - hypermetabolic mass in the left side mandible with the bone lesion (SUVmax 15.9) (1) and involved submandibular hypermetabolic lymph nodes (SUVmax 11.3) (2). H - WB FDG-PET scan in lateral projection showing hypermetabolic activity on the left side of the mandible (A) and adjacent lymph nodes (B), as well as in the arch of L5 (C). I - FDG-PET and CT fusion image with a hypermetabolic mass in the arch of L5, which resulted in a bone lesion (SUVmax 11.4)

Survivors may experience long-term permanent consequences that include endocrine disorders (DI and growth hormone deficiency), orthopaedic problems, decreases or loss in hearing and sight, the loss of teeth, neurological defects (which affect the CNS in up to 30\% of cases), and impaired lung and liver function [2, 17, 35,
37, 38]. Among the most potentially devastating complications is ND-CNS-LCH. Patients with LCH have a higher risk for developing secondary cancers (leukaemia and non-Hodgkin lymphoma) [2].

Thus, the broad spectrum of clinical symptoms and rarity of LCH make the diagnosis difficult. The unclear nature, the 

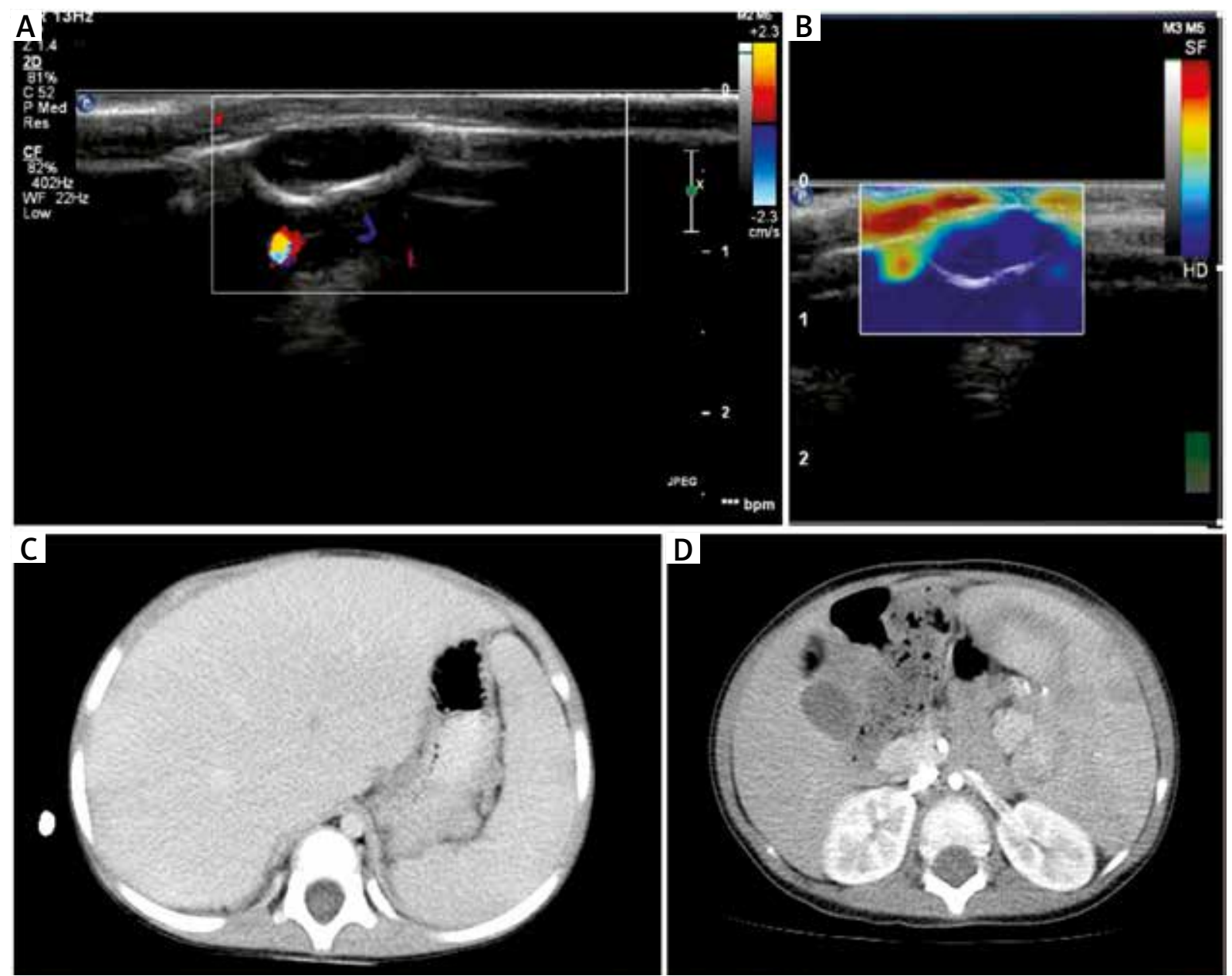

Figure 2. A - Ultrasonography (1HX1 elastography) of the intraosteal cyst of the temporal bone with no visible features of bone destruction. B - Ultrasonography (1HX1 elastography) of a solid lesion in the right parietal area with bone destruction. The blue colour corresponds to a hard lesion, and the image suggests a proliferative process. $\mathrm{C}-\mathrm{Computed}$ tomography (CT) of the abdomen - hepatomegaly. D - Computed tomography (CT) of the abdomen - splenomegaly

heterogeneous course of the disease from an asymptomatic form to those with various clinical symptoms, the diverse prognosis and the risk of long-term complications cause LCH to remain a major challenge for medicine. However, many years of experience indicate that both the diagnosis and treatment of this disease are becoming more successful.

\section{Conflict of interest}

The authors declare no conflict of interest.

\section{References}

1. Emile JF, Abla O, Fraitag S, et al. Revised classification of histiocytoses and neoplasms of the macrophage-dendritic cell lineages. Blood 2016; 127: 2672-81.

2. Haupt R, Minkov M, Astigarraga I, et al. Langerhans cell histiocytosis (LCH): guidelines for diagnosis, clinical work-up, and treatment for patient till age of 18 years. Pediatr Blood Cancer 2013; 60: 175-84.
3. Minkov M. Multisystem Langerhans cell histiocytosis in children. Current treatment and future directions. Pediatr Drugs 2011; 13: 75-86.

4. Margo CE, Goldman DR. Langerhans cell histiocytosis. Surv Ophthalmol 2008; 53: 332-58.

5. Grana N. Langerhans cell histiocytosis. Cancer Control 2014; 21: 328-34.

6. Postini AM, Brach del Prever A, Pagano M, et al. Langerhans cell histiocytosis: 40 years' experience. J Pediatr Hematol Oncol 2012; 34: 353-58.

7. Minkov M, Grois N, McClain K, et al. Langerhans cell histiocytosis - Histiocyte Society Evaluation and Treatment Guidelines, Protocol, April 2009.

8. Abla O, Egeler RM, Weitzman S. Langerhans cell histiocytosis: current concepts and treatments. Cancer Treat Rev 2010; 36: 354-59.

9. Donadieu J, Chalard F, Jeziorski E. Medical management of Langerhans cell histiocytosis from diagnosis to treatment. Expert Opin Pharmacother 2012; 13: 1309-22.

10. Windebank K, Naduri V. Langerhans cell histiocytosis. Arch Dis Child 2009; 94: 904-8. 
11. Morren MA, Broecke KV, Vangeeebergen L, et al. Diverse cutaneous presentations of Langerhans cell histiocytosis in children: a retrospective cohort study. Pediatr Blood Cancer 2016; 63: 486-92.

12. Morimoto A, Ishida Y, Suzuki N, et al. Nationwide survey of single-system single site Langerhans histiocytosis in Japan. Pediatr Blood Cancer 2010; 54: 98-102.

13. Alston RD, Tatevossian RG, McNally RJ, et al. Incidence and survival of childhood Langerhans cell histiocytosis in Northwest England from 1954 to 1998. Pediatr Blood Cancer 2007; 48: 555-60.

14. Guyot-Goubin A, Donadieu J, Barkaoui M, et al. Descriptive epidemiology of childhood Langerhans cell histiocytosis in France, 2000-2004. Pediatr Blood Cancer 2008; 51: 71-5.

15. Ronceray L, Potschger U, Janka G, et al. Pulmonary involvement in pediatric-onset multisystem Langerhans cell histiocytosis: effect on course and outcome. J Pediatr 2012; 161: 129-33.

16. Braier J, Latella A, Balancini B, et al. Outcome in children with pulmonary Langerhans cell histiocytosis. Pediatr Blood Cancer 2004; 43: 765-69.

17. Morimoto A, Oh Y, Shioda Y, et al. Recent advances in Lang erhans histiocytosis. Pediatr Int 2014; 56: 451-61.

18. Zinn DJ, Chakraborty R, Allen CE. Langerhans cell histiocytosis: emerging insights and clinical implications. Oncol J 2016; 30: 122-39.

19. Sakata N, Toguchi N, Kimura M, et al. Development of Lang erhans cell histiocytosis associated with chronic active Epstein-Barr virus infection. Pediatr Blood Cancer 2008; 50 : 924-7.

20. Murakami I, Matsushita M, Iwasaki T, et al. Merkel cell polyomavirus DNA sequences in peripheral blood and tissues from patients with Langerhans cell histiocytosis. Hum Pathol 2014; 45: 119-26.

21. Bechan GL, Egeler RM, Arceci RJ. Biology of Langerhans cells and Langerhans cell histiocytosis. Int Rev Cytol 2006; 254 : 1-43.

22. Allen CE, Li L, Peters TL, et al. Cell specific gene expression in Langerhans cell histiocytosis lesions reveals a distinct profile compared with epidermal Langerhans cells. J Immunol 2010; 184: 4557-67.

23. Senechal B, Elain G, Jeziorski E, et al. Expansions of regulatory $T$ cells in patients with Langerhans cell histiocytosis. PLoS Med 2007; 4: e253,1374-84.

24. Murakami I, Morimoto A, Oka T, et al. IL-17A receptor expres sion differs between subclasses of Langerhans cell histiocytosis, which might settle the IL-17A controversy. Virchows Arch 2013; 462: 219-28.

25. Willman CL, Busque L, Griffith BB, et al. Langerhans'-cell histiocytosis (histiocytosis X) - a clonal proliferative disease. N Engl J Med 1994; 331: 154-60.

26. Yu RC, Chu C, Buluvela L, Chu AC. Clonal proliferation of Langerhans cells in Langerhans histiocytosis. Lancet 1994; 343: 767-8.

27. Berres ML, Merad M, Allen CE. Progress in understanding the pathogenesis of Langerhans cell histiocytosis: back to histiocytosis X? Br J Haematol 2015; 169: 3-13.

28. Brown NA, Furtado LV, Betz BL, et al. High prevalence of somatic MAP2K1 mutations in BRAF V600E-negative Langerhans cell histiocytosis. Blood 2014; 124: 1655-58.

29. Sasaki Y, Guo Y, Arakawa F, et al. Analysis of the BRAFV600E mutation in 19 cases of Langerhans histiocytosis in Japan. Hematol Oncol 2017; 35: 329-34
30. Badalian-Very G, Vergilio JA, Degar BA, et al. Reccurrent BRAF mutations in Langerhans histiocytosis. Blood 2010; 116: 1919-23.

31. Berres ML, Lim KP, Peters T, et al. BRAF-V600E expression in precursors versus differentiated dendritic cells defines clinically distinct LCH risk groups. J Exp Med 2014; 211: 669-83.

32. Lau SK, Chu PG, Weiss LM. Immunohistochemical expression of langerin Langerhans cell histiocytosis and non-histiocytic disorders. Am J Surg Pathol 2008; 32: 615-9.

33. Filipovich A, McClain K, Grom A. Histiocytic disorders: recent insights into pathophysiology and practical guidelines. Biol Blood Marrow Transplant 2010; 16: S82-89.

34. Weitzman S, Egeler RM. Langerhans cell histiocytosis: update for the paediatrician. Curr Opin Pediatr 2008; 20: 23-9.

35. Haupt R, Nanduri V, Calevo MG, et al. Permanent consequences in Langerhans histiocytosis patients: a pilot study from the Histiocyte Society-Late Effects Study Group. Pediatr Blood Cancer 2004; 42: 438-44.

36. Pollono D, Rey G, Latella A, et al. Reactivation and risk sequelae in Langerhans cell histiocytosis. Pediatr Blood Cancer 2007; 48: 696-9.

37. Fahrner B, Prosch H, Minkov M, et al. Long-term outcome of hypothalamic pituitary tumors in Langerhans cell histiocytosis. Pediatr Blood Cancer 2012; 58: 606-10.

38. Lau LM, Stuurman K, Weitzman S. Skeletal Langerhans histiocytosis in children: permanent consequences and healthrelated quality of life in long-term survivors. Pediatr Blood Cancer 2008; 50: 607-12.

39. Grois N, Potschger U, Prosch H, et al. Risk factors for diabetes insipidus in Langerhans histiocytosis. Pediatr Blood Cancer 2006; 46: 228-33.

40. McClain KL. Drug therapy for the treatment of Langerhans cell histiocytosis. Expert Opin Pharmacother 2005; 6: 2435-41.

41. Gadner H, Grois N, Potschger U, et al. Improved outcome in multisystem Langerhans cell histiocytosis is associated with therapy intensification. Blood 2008; 111: 2556-61.

42. Gadner H, Minkov M, Grois N. Therapy prolongation improves outcome in multisystem Langerhans cell histiocytosis. Blood 2013; 121: 5006-14.

43. Khung S, Budzik JF, Amzallag-Bellenger E, et al. Skeletal involvement in Langerhans cell histiocytosis. Insights Imaging 2013; 4: 569-79.

44. Stull MA, Kransdorf MU, Devaney KO. Langerhans cell histiocytosis of bone. Radiographics 1992; 12: 801-23.

45. Battistella M, Fraitag S, Teillac DH, et al. Neonatal and early infants cutaneous Langerhans cell histiocytosis: comparison of self-regressive and non-self regressive forms. Arch Dermatol 2010; 146: 149-56.

46. Ng SSY, Koh MJA, Tay YK. Cutaneous Langerhans cell histiocytosis: study of Asian children show good overall prognosis. Acta Paediatr 2013; 102: 514-8.

47. Lau L, Krafchik B, Trebo MM, et al. Cutaneous Langerhans cell histiocytosis in children under one year. Pediatr Blood Cancer 2006; 46: 66-71.

48. Simko SJ, Garmezy B, Abhyankar H, et al. Differentiating skin-limited and multisystem Langerhans cell histiocytosis. J Pediatr 2014; 165: 990-6.

49. Lasek-Duriez A, Charkaluk ML, Gosset P, Mondiano P. Blueberry muffin baby and Langerhans congenital cell histiocytosis. Ann Dermatol Venereol 2014; 141: 130-3.

50. Chander R, Jaykar K, Varghese B, et al. Pulmonary disease with striking nail involvement in a child. Pediatr Dermatol 2008; 25: 633-34. 
51. Edelweiss M, Medeiros LJ, Suster S, Moran CA. Lymph node involvement by Langerhans cell histiocytosis: a clinicopathologic and histochemical study of 20 cases. Hum Pathol 2007; 38: 1463-9.

52. Hicks J, Flaitz CM. Langerhans cell histiocytosis: current insights in a molecular age with emphasis on clinical oral and maxillofacial pathology practice. Oral Surg Oral Med Oral Pathol Oral Radiol Endod 2005; 100: S42-66.

53. Madrigal-Martinez-Pereda C, Guerrero-Rodriguez V, Guisado-Moya B, Meniz-Garcia C. Langerhans cell histiocytosis: literature review and descriptive analysis of oral manifestations. Med Oral Patol Oral Cir Bucal 2009; 14: E222-28.

54. Laurencikas E, Gavhed D, Stalemark H, et al. Incidence and pattern of radiological central nervous system Langerhans cell histiocytosis in children: a population based study. Pediatr Blood Cancer 2011; 56: 250-7.

55. Grois NG, Favara BE, Mostbeck GH, Prayer D. Central nervous system disease in Langerhans cell histiocytosis. Hemato Oncol Clin North Am 1998; 12: 287-305.

56. Allen CE, Flores R, Rauch R, et al. Neurodegenerative centra nervous system Langerhans cell histiocytosis and coincident hydrocephalus treated with vincristine/cytosine arabinoside. Pediatr Blood Cancer 2010; 54: 416-23.

57. Imashuku S, Arceci RJ. Strategies for the prevention of central nervous system complications in patients with Langerhans cell histiocytosis. The problem of neurodegenerative syndrome. Hematol Oncol Clin N Am 2015; 29: 875-93.

58. Porto L, Schöning S, Hattingen E, et al. Central nervous system imaging in childhood Langerhans cell histiocytosis - a reference center analysis. Radiol Oncol 2015; 49: 242-9.

59. Grois N, Fahrner B, Arcecci RJ, et al. Central nervous system disease in Langerhans histiocytosis. J Pediatr 2010; 156 873-81.

60. Donadieu J, Rolon MA, Pion I, et al. Incidence of growth hormone deficiency in pediatric-onset Langerhans cell histiocytosis: efficacy and safety of growth hormone treatment. J Clin Endocrinol Met 2004; 89: 604-9.

61. Grois N, Prayer D, Prosch H, et al. Course and clinical impact of magnetic resonance imaging findings in diabetes insipidus associated with Langerhans histiocytosis. Pediatr Blood Cancer 2004; 43: 59-65.

62. Imashuku S. High dose immunoglobulin (IVIG) may reduce the incidence of Langerhans cell histiocytosis (LCH)-associated central nervous system involvement. CNS Neurol Disord Drug Targets 2009; 8: 380-6.

63. Grois N, Prayer D, Prosch H, et al. CNS LCH Co-operative Group. Neuropathology of CNS disease in Langerhans cell histiocytosis. Brain 2005; 128: 829-38.

64. Imashuku S, Okazaki N, Nakayama M, et al. Treatment of neurodegenerative CNS disease in Langerhance cell histiocytosis with combination of intravenous immunoglobulin and chemotherapy. Pediatr Blood Cancer 2008; 50: 308-11.

65. Sieni E, Barba C, Mortilla M, et al. Early diagnosis and monitoring of neurodegenerative Langerhans cell histiocytosis. PLoS One 2015; 10: e0131635.

66. Wnorowski M, Prosch H, Prayer D, et al. Pattern and course of neurodegeneration in Langerhans cell histiocytosis. J Pediatr 2008; 153: 127-32.

67. Krenova Z, Sterba J. Langerhans cell histiocytosis: the time has come to consider a CNS-directed prophylactic approach. J Pediatr Hematol Oncol 2016; 38: 493-5.

68. Imashuku S, Shioda Y, Morimoto A. CNS-directed prophylactic approach to Langerhans cell histiocytosis. J Pediatr Hematol Oncol 2017; 39: 321-2.
69. Wong A, Ortiz-Neira CL, Reslan WA, et al. Liver involvement in Langerhans cell histiocytosis. Pediatr Radiol 2006; 36 : 1105-7.

70. Yi X, Han T, Zai H, et al. Liver involvement of Langerhans' cell histiocytosis in children. Int J Clin Exp Med 2015; 8: 7098106.

71. Braier J, Ciocca M, Latella A, et al. Cholestasis, sclerosing cholangitis, and liver transplantation in Langerhans cell histiocytosis. Med Pediatr Oncol 2002; 38: 178-82.

72. Ducassou S, Seyrig F, Thomas C, et al. Thymus and mediastinal node invovement in childhood Langerhnas cell histiocytosis: long-term follow-up form the French National Cohort. Pediatr Blood Cancer 2013; 60: 1759-65.

73. Yagci B, Varan A, Üner A, et al. Thymic Langerhans histiocytosis mimicking lymphoma. Pediatr Blood Cancer 2008; 51: 833-5.

74. Minkov M, Pötschger U, Grois N, et al. Bone marrow assessment in Langerhans histiocytosis. Pediatr Blood Cancer 2007; 49: 694-8.

75. Raney BR, D”Angio GJ. Langerhans cell histiocytosis (histiocytosis X): experience at the Children's Hospital of Philadelphia, 1970-1984. Med Pediatr Oncol 1989; 17: 20-8.

76. Favara BE, Jaffe R, Egeler RM. Macrophage activation and hemophagocytic syndrome in Langerhans histiocytosis: report of 30 cases. Pediatr Dev Pathol 2002; 5: 130-40.

77. Suri HS, Yi ES, Nowakowski GS, Vasallo R. Pulmonary Langerhans cell histiocytosis. Orphanet J Rare Dis 2012; 7: 16-29.

78. Howarth DM, Gilchrist GS, Mullan BP, et al. Langerhans cell histiocytosis: diagnosis, natural history, management and outcome. Cancer 1999; 85: 2278-90.

79. Braier J, Latella A, Balancini B, et al. Isolated pulmonary Langerhans cell histiocytosis presenting with recurrent pneumothorax. Pediatr Blood Cancer 2007; 48: 241-4.

80. Odame I, Li P, Lau L, et al. Pulmonary Langerhans cell histiocytosis: a variable disease in childhood. Pediatr Blood Cancer 2006; 47: 889-93.

81. Hait E, Liang M, Degar B, et al. Gastrointestinal tract involvement in Langerhans cell histiocytosis: case report and literature review. Pediatrics 2006; 118: e1593-9.

82. Singhi AD, Montgomery EA. Gastrointestinal tract Langerhans cell histiocytosis: a clinicopathologic study of $12 \mathrm{pa-}$ tients. Am J Surg Pathol 2011; 35: 305-10.

83. Shima H, Takahashi T, Shimada H. Protein-losing enteropathy caused by gastrointestinal tract-involved Langerhans cell histiocytosis. Pediatrics 2010; 125: e426-32.

84. Yadav SP, Kharya G, Mohan N, et al. Langerhans cell histiocytosis with digestive tract involvement. Pediatr Blood Cancer 2010; 55: 748-53.

85. Lakatos K, Herbrüggen $\mathrm{H}$, Pötschger U, et al. Radiological features of thymic Langerhans histiocytosis. Pediatr Blood Cancer 2013; 60: E143-5.

86. Lin CH, Lin WC, Chiang IP, et al. Langerhans cell histiocytosis with thyroid and lung involvement in a child: a case report. J Pediatr Hematol Oncol 2010; 32: 309-11.

87. Goyal R, Das A, Nijhawan R, et al. Langerhans histiocytosis infiltration into pancreas and kidney. Pediatr Blood Cancer 2007; 49: 748-50.

88. Chaudhary V, Bano S, Aggarwal R, et al. Neuroimaging of Langerhans cell histiocytosis: a radiological review. Jpn J Radiol 2013; 31: 786-96.

89. Goo HW, Yang DH, Ra YS, et al. Whole-body MRI of Langerhans histiocytosis: comparison with radiography and bone scintigraphy. Pediatr Radiol 2006; 36: 1019-31. 
90. Kaste SC, Rodriquez-Galindo C, McCarville ME, Shulkin BL. PET-CT in pediatric Langerhans histiocytosis. Pediatr Radiol 2007; 37: 615-22.

91. Philips M, Allen C, Gerson P, McClain K. Comparison of FDG-PET scans to conventional radiography and bone scans in management of Langerhans cell histiocytosis. Pediatr Blood Cancer 2009; 52: 97-101.

92. Gatidis S, Bender B, Reimold M, Sch fer JF. PET/MRI in children. Eur J Radiol 2017; 94: A64-70.

93. Kosiak W, Piskunowicz M, Świętoń D, et al. Sonographic diagnosis and monitoring of localized Langerhans cell histiocytosis of the skull. J Clin Ultrasound 2013; 41: 134-9.

94. Simko SJ, Tran HD, Jones J, et al. Clofarabine salvage therapy in refractory multifocal histiocytic disorders, including Langerhans cell histiocytosis, juvenile xantogranuloma and Rosai-Dorfman disease. Pediatr Blood Cancer 2014; 61: 479-87.

95. Davidson L, McComb JG, Bowen I, Krieger MD. Craniospinal Langerhans cell histiocytosis in children: 30 years' experience at a single institution. J Neurosurg Pediatr 2008; 1: 187-95.

96. Imashuku S, Fujita N, Shioda Y, et al. Follow-up of pediatric patients treated by IVIG for Langerhans cell histiocytosis (LCH)-related neurodegenerative CNS disease. Int J Hematol 2015; 101: 191-7.

97. Idbaih A, Donadieu J, Barthez MA, et al. Retinoic acid therapy in "degenerative-like" neuro-Langerhans cell histiocytosis: a prospective pilot study. Pediatr Blood Cancer 2004; 43: 55-8.

98. Tweedie D, Sambamurti K, Greig NH. TNF-alpha inhibition as a treatment strategy for neurodegenerative disorders: new drug candidates and targets. Curr Alzheimer Res 2007; 4: 378-85.

99. Uppuluri R, Ramachandrakurup S, Balaji R, et al. Successful treatment of refractory Langerhans cell histiocytosis of the choroid plexus in a child with pulse dexamethasone and lenalidomide. J Pediatr Hematol Oncol 2017; 39: e74-8.

100. Uppuluri R, Ramachandrakurup S, Subburaj D, et al. Excellent remission rates with limited toxicity in relapsed/refractory Langerhans histiocytosis with pulse dexamethasone and lenalidomide in children. Pediatr Blood Cancer 2017; 64: 110-2.

101. Baumann M, Cerny T, Sommacal A, et al. Langerhans cell histiocytosis with central nervous system involvementcomplete response to 2-chlorodeoxyadenosine after failure of tyrosine kinase inhibitor therapies with sorafenib and imatinib. Hematol Oncol 2012; 30: 101-4.

102. Savardekar A, Tripathi M, Bansal D, et al. Isolated tumorous Langerhans cell histiocytosis of the brainstem: a diagnostic and therapeutic challenge. J Neurosurg Pediatr 2013; 12: 258-61.

103. Euskirchen P, Haroche J, Emile JF, et al. Complete remission of critical neurohistiocytosis by vemurafenib. Neurol Neuroimmunol Neuroinflamm 2015; 2: e78.

104. Minkov M, Hutter C. Insights into the pathogenesis of Langerhans histiocytosis: the development of targeted therapies. Immunotargets Ther 2016; 5: 81-91.

105. Yagci B, Varan A, Caglar M, et al. Langerhans cell histiocytosis: retrospective analysis of 217 cases in single centre. Pediatr Hematol Oncol 2008; 25: 399-408.

106. Jubran RF, Marachelian A, Dorey F, Malogolowkin M. Predictors of outcome in children with Langerhans histiocytosis. Pediatr Blood Cancer 2005; 45: 37-43. 